\section{SCIENCE IN EGYPT}

By Prof. MAX BORN, F.R.S., and L. J. F. BRIMBLE

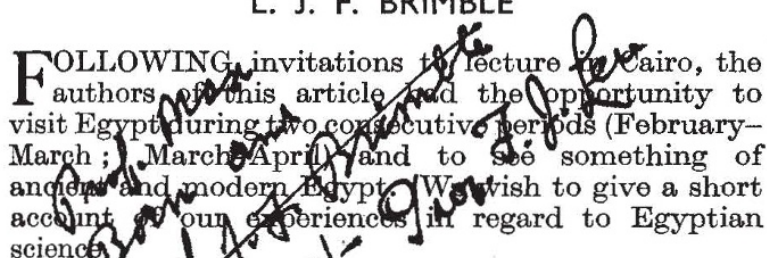

Cair has dides hostitution in the world which deserves tho hame of a university, namely, El Azhar, founded in 972 p. (361 of the Hegira), a school of Mohammedan refigion, law, history and literature which in pre-war times had about 17,000 students and at present has more than 12,000 . In fact, Mohammedan students from all over the world attend this institution, which is the chief theological seminary of Islam. Teaching of the Qur'an (Koran) is its physics are behind that again. On the right is the library. At some distance off to the left are the Faculties of Agriculture and Engineering. There will be scarcely any European university which can compete in lay-out and architectural beauty with this campus. The Egyptians had the advantage of the past experiences of most other universities, and they have not lost this unique opportunity. What we have seen of the lecture rooms and laboratories, the Great Auditorium (Fig. 2) and the administration quarters, is well designed and in excellent taste. Behind the campus stretches a wide area for sport and physical exercise, with large stadia, swimming pools and other buildings, all in the same grand manner. The Faculty of Medicine is situated on Roda Island (where according to tradition the babe Moses was discovered), and at Kasr el Ani.

Buildings for mathematics, chemistry, etc., are com. pleted and those of other sciences are planned or in construction. The Departments are to-day provisionally crammed partly (junior classes) into the existing

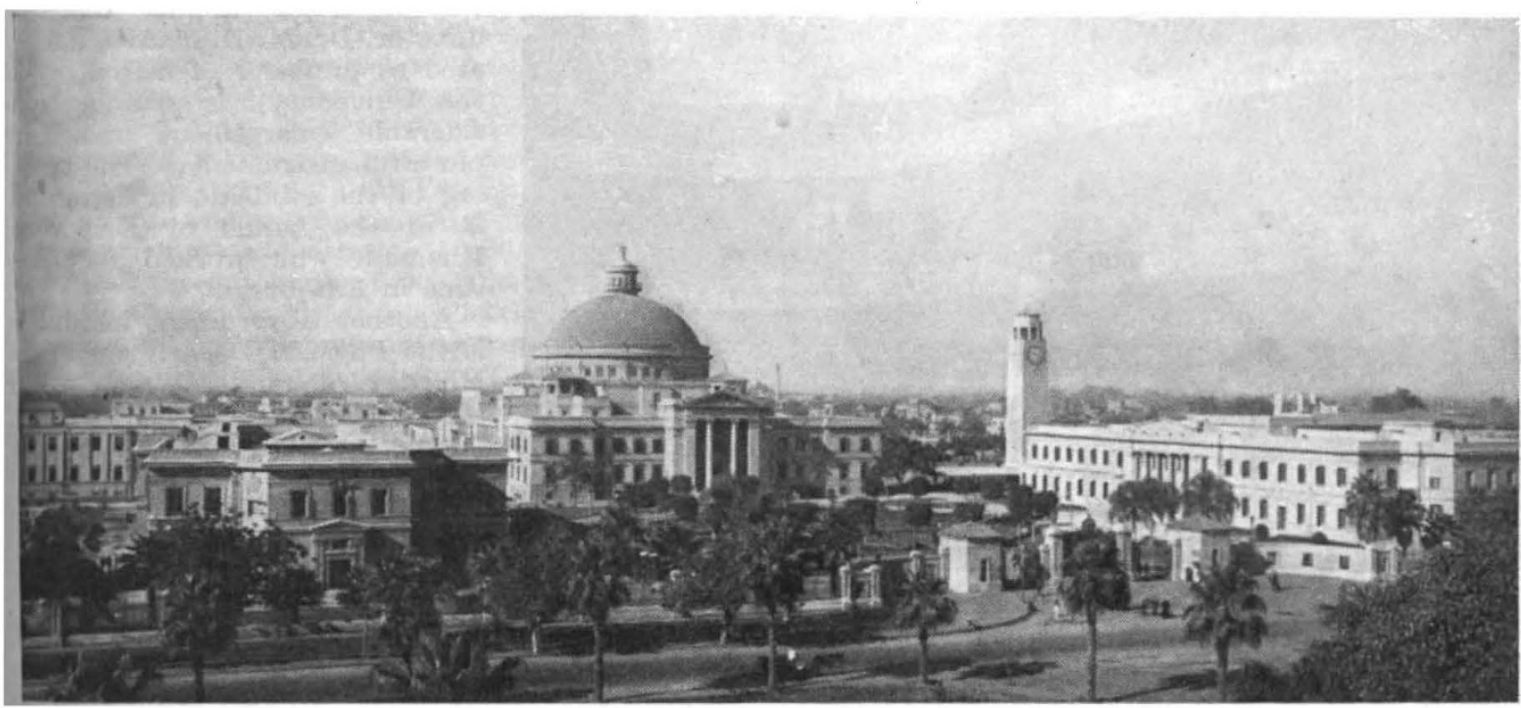
Fig. 1: GENERAL VIEW OF PART OF THE NEW UNIVERSITY OAMPUS. IN THE CENTRE IS THE GREAT HALL WITH ITS IMP RESSIVE ROTUNDA;
TO THE RIGHT ARE THE LIBRARY AND CLOCK TOWER; TO THE LEFT IS THE FACULTY OF LAW WITH PART OF THE BIOLOGICAL BULDINGS TO THE RIGHT ARE THE LIBRARY AND CLOCK TOWER; TO THE LJET IS THE FACULTY OF LAW WITH PART OF THE BIOLOGICAL BUILDINGS
BEHIND. THERE ARE MANY OTHER BUILDINGS (MAINLY SCIENCE) BEHIND THE GREAT HALI. THE FACULTIES OF AGRICULTURE AND ENGINEERING ARE OFF THE PICTURE TO THE LEFT

main object, and the full course lasts seventeen years. Parts of civil law, in particular everything concerned with family life, marriage, divorce, are still in the hands of courts based on this School, while the rest of juridical life is practised by courts of more modern origin and education, coming from the law school of Cairo's new University.

The new University was founded in 1925 by King Fouad I with the purpose of developing and teaching modern ideas and techniques. Fouad I University (as it was called after 1940) has at present eight faculties-arts, science, law, engineering, medicine, commerce, agriculture and veterinary medicine. Most of them are housed on a magnificent campus situated on the left bank of the Nile, in the suburb of Giza, on the road to the Pyramids, in a group of splendid modern buildings. Fig. 1 shows only a part of the central University area. The Great Auditorium with its magnificent rotunda is opposite the main gates. On the left is the Faculty of Law and (behind) some of the biological buildings. Chemistry and buildings, partly (advanced classes and research) still at the original site of the University, at El Zafaran Palace in Abbassia-a northern suburb of Cairo. This partition is most inconvenient as the distance between Giza and Abbassia is more than six miles. It is hoped, however, that the whole Faculty of Science will have settled at Giza by 1950.

The rector of the University is Ali Ibrahim Pasha, the well-known surgeon. The present dean of the Faculty of Science is Prof. A. M. Mosharrafa Pashe, professor of applied mathematics. His publications are mostly concerned with problems of relativity, but he is interested in all branches of theoretical physics. Mosharrafa is a brilliant administrator and organiser; and he, together with former deans of the Faculty of Science and of other faculties, have, under the eminently wise guidance of Ali Ibrahim Pasha, been responsible for the developments which have led to the establishment and growth of this University. The head of the Department of Pure Mathematics is Prof. M. Mursi Ahmad, trained at 


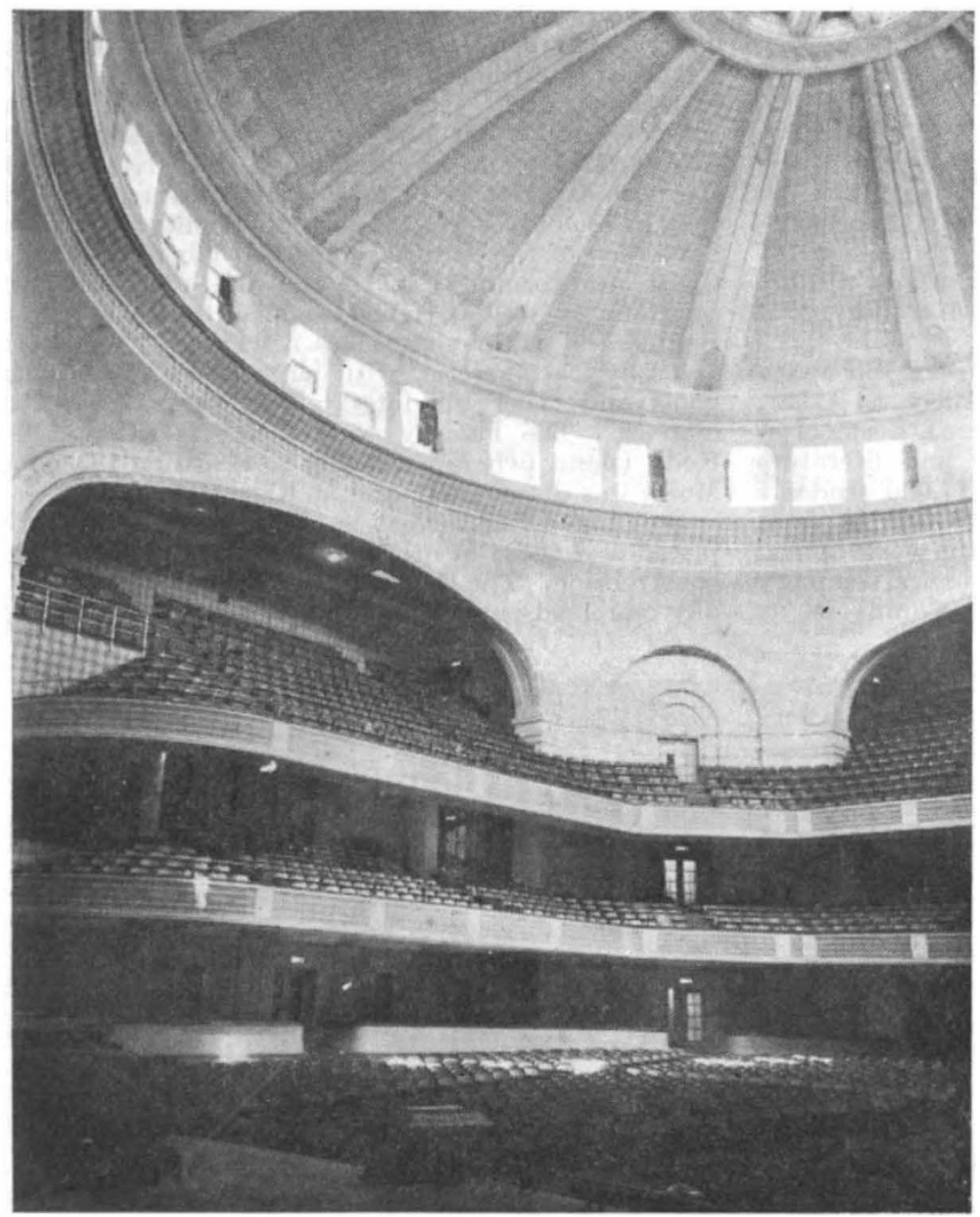

Fig. 2. INTTRior of the Great HaLL

Whittaker's School in Edinburgh. Dr. E. L. Ince was formerly the professor of that Department. As one of us had the opportunity of acting as external examiner for the advanced class of one of these Departments, we can compare its standard with British schools; the result is that it is very high and of the same level as Edinburgh. It might be pointed out incidentally that the external examiners for all final examinations and higher degrees in the Faculty of Science are men of science outside Egypt altogether-mainly professors in British universities. These examiners are asked to maintain a standard for Cairo equal to that of their own universities.

Prof. T. L. R. Ayres is director of the physical laboratories, where a great number of students are taught and research work on supersonies is done. There is also a physics department attached to the Faculty of Engineering under Dr. A. Waly, who was trained in Germany and is mainly interested in nuclear physics.

Chemistry under Prof. A. Schoenberg (whose communications in Nature have been spread over a long period) is a very big Department with a wide research programme, concerning photochemical reactions in sunlight, the synthesis of substances with sex-hormone properties (non-steroid œstrogens) and their applications. The latter are worked out in collaboration partly with Dr. J. M. Robson in Edin- burgh (prolonged action on mice, low toxicity) and partly with Prof. Ahmed Ghonein, Faculty of Agriculture, Cairo. A remarkable result of this work may be mentioned. Hens receiving 'stilbene' began to lay eggs more than one month earlier than the control group. Former professors of chemistry have been Dr. E. C. Grey, Dr. D. H. Bangham (also dean of the Faculty) who is now attached to the British Coal Utilisation Research Association, and Dr. Ahmed Zaki Bey.

The Government has an astronomical observatory near Helwan, some twenty miles south of Cairo, situated on the fringe of the Eastern Desert, overlooking the wide valley of the Nile.

The climate of Egypt is most favourable for astronomical work, and it is no wonder that the director, Dr. M. R. Madwar (delegated as professor of astronomy in the University), is planning considerable enlargement and more powerful instruments. The teaching of the students in astronomy is in the hands of Dr. Abdel Rhaman, who worked for some time in Edinburgh.

Another Government institution is the Physical Department of the Ministry of Public Works, under the directorship of Dr. H. E. Hurst. Its main activities are meteorology and research on the Nile. But apart from that, Hurst's laboratories have done most useful service to the country, and also to the British Army during the War, by constructing and producing all kinds of scientific instruments which could not be supplied from Europe. In fact, part of the buildings look still more like factories than laboratories. The meteorological service works on the usual lines; under the special conditions of Egypt, however, forecasts seem to be easier and more reliable than in many other parts of the world. Apart from the Delta, there is scarcely any rain along the Nile valley, and 'bad weather' means the Chamsin, the hot desert wind loaded with dust. (However, one of us has experienced two heavy thunderstorms with torrential rains during a two months' stay.) The control of the water of the Nile is the result of more than forty years study and research and is one of the outstanding results of science in Egypt. An explanation of the regulation of the Nile, with its barrages, reservoirs, irrigation and drainage canals, would exceed the space of this article. The administration of this enormous system, which produces three or even four crops a year, is an admirable organisation. Each single fellah (Egyptian peasant) has definite hours allocated to draw water into his field from the irrigation ditch. All this depends on the exact forecast of the water available at a given time, and this again on the knowledge of the flux in all parts of the river, from the Blue and the White Nile down to the last canal. Exact measurements of the current over the whole area of the river and the canals are therefore neces- 
sary, and the State Laboratories construct and produce the instruments used for this purpose. The velocity is measured by a kind of small turbine, and as the flow in many canals is very slow the sensitivity of these indicators must be correspondingly high. The Department is also concerned with future improvements of the system, such as the planned drainage of the Sud region in the Sudan, where at present a great proportion of the Nile water is lost by evaporation in swamps; the plan for a barrage at the mouth of Lake Albert, etc. Blocking of the channels of the White Nile, together with the transpiration of the swamp vegetation, is responsible for a loss of about 70 per cent of the water between the great lakes and Malakal. An expedition was sent from the Botany Department of the University this year to study the problem; another will be sent next year.

Another big scheme already in construction is a new dam near Aswan for producing hydro-electric power. The chief engineer for this project is Abdul Aziz Achmed Bey. The main purpose of this is the manufacture of artificial manure to replace the natural silt deposits which under the present system of perennial agriculture are lost in the reservoirs.

Agriculture is, of course, the main industry of the country, and much is done to improve it. There are Government departments for research, a Royal Agricultural Society with an Exhibition Ground on Gezira Island, and an excellent Agricultural Museum. It consists of several attractive buildings in lovely gardens on the left bank of the Nile, north of Giza. One of these contains historical collections, everything found in tombs and temples of ancient Egypt which is concerned with agriculture. There are reliefs showing all types of farming, of animals and plants down to the times when the Pyramids were built; mummies of wild and domesticated animals; and seeds of numerous plants found in the tombs. Within the grounds of the Royal Agricultural Society there is also a separate Cotton Museum. Both these museums are splendid examples of up-to-date methods in visual education.

The other buildings contain representations of modern farming in lively models, pictures and graphs. It was pleasant to see crowds of simple folk, obviously peasants in their best, thronging these rooms and halls, deeply interested in the methods demonstrated by the exhibitions. In fact, life and work of the Egyptian fellah is still primitive and hard; much has to be done to raise his standard of living. But a beginning is being made.

Though most of the new buildings at Giza designed to house the Departments of Mathematics, Chemistry and Geology were completed by 1939, it was not until 1942 that a building was adapted for the Department of Botany and Zoology. Teaching, and even part of the research, therefore, is still divided between the old buildings at Abbassia and the new ones at Giza. The Faculty of Science was also necessarily partially disturbed by the Army authorities during the War. In spite of this, the biological departments are large, with many demonstrators who are themselves reading for M.Sc. degrees. A considerable number of M.Sc. and Ph.D. degrees are awarded each year for research.

The Botany Department has two professorsProf. F. J. Lewis (who has just resigned his chair) and Prof. Y. S. Sabet. Under them is a staff of very active lecturers and demonstrators carrying on research in plant physiology, morphology, taxonomy, elocogy and mycology. Reference has already been made to some of the botanical field work. Previous professors of botany have been Dr. Gunnar Tackholm, who, together with his wife, was compiling a comprehensive flora of Egypt (Mrs. Tackholm is continuing this work, see Nature of May 11, p. 635), Dr. F. W. Oliver and Dr. F. E. Weiss (the last-named only temporarily).

The Department of Zoology devotes much attention to experimental zoology, though work on animal morphology, anatomy and taxonomy is also being done. The results of some of this work is now appearing in Nature in the correspondence columns. The present director of the Zoology Department is Prof. K. Mansour. Former professors were Dr. V. Jollos and Dr. A. Naef (the last-named still enjoying the status of visiting professor of zoology (comparative anatomy) ).

Entomology is a small department so far as number of students is concerned, but not as regards activity, for the well-known Prof. H. C. Efflatoun Bey is in charge. Efflatoun Bey has done invaluable work on the insects of Egypt and published mainly in the Proceedings of the Royal Entomological Society of Egypt (see Nature of July 6, p. 35). This scientific society is one of Egypt's most active, with a magnificent building, housing museum, lecture theatre, research rooms, etc., in the centre of Cairo. The Entomological Department of the University and the Royal Entomological Society have also collaborated with expeditions abroad dealing with locust problems.

Geology is under the direction of Prof. O. Zdansky. A former professor was Dr. I. Hoegborn, who was also dean of the Faculty for two years.

Outside the Faculty of Science, there are other University scientific activities. For example, there is a large Faculty of Agriculture and Horticulture at Giza. This has departments of botany, entomology, agriculture and agricultural engineering. The large Department of Horticulture has extensive experimental and ornamental gardens. There are wellequipped laboratories for plant food products where problems of food preservation, canning and dehydration are being attacked. Research is also being carried out on the vitamin content of fruit and vegetables. Valuable work is also being done on the silk worm.

Then there is the Cotton Research Board, which also has its well-equipped laboratories, under the direction of Dr. W. Lawrence Balls, housed at Giza (see Nature of July 6, p. 9). Here for more than twenty-five years research has been conducted on the breeding, growing and physiology of the cotton plant, and the economic uses of different varieties of cotton, the quality and treatment of the fibre. This is the centre of the cotton industry in Egypt, and the successful development of the industry is due entirely to the work carried on in these laboratories.

Much work of scientific value is also being carried out in the Faculties of Fngineering and of Medicine; but time would not allow either of us to visit these centres of teaching and research.

The museums in Cairo have attained a particularly high standard. The Cotton Museum and the Museum of the Ministry of Agriculture have already been mentioned. In these, great ingenuity has been shown in devising methods (mainly electrical) for driving home important points. Those interested in visual education should not miss these institutions if visiting Cairo. Then there is, of course, the world-famous Cairo Museum containing many important antiquities 
including those of Tutankhamun. What we did miss, however, were a natura.l history museum and a general science museum corresponding respectively to the British Museum (Natural History) and the Science Museum (dealing mainly with engineering achievements) respectively. The Egyptian authorities have already shown special ingenuity in the organisation of their museums, so we hope they will extend their valuable work to include these others.

Science is certainly developing seriously and quickly in Egypt. Only those places visited by us have been briefly described here, but we hope it is enough to indicate that the academic and government authorities in Egypt are showing a deep appreciation of the value of science. An Egyptian Academy of Sciences is now flourishing and will soon begin its own publications. This was described by Mosharrafa Pasha in Nature of May 4, p. 573. The Faculty of Science is also publishing a general scientific journal which, we hope, will achieve national proportions in due course.

The Farouk University at Alexandria has yet to get into its stride; but we have little doubt that there too, in due course, will be developed another modern centre of science and culture.

We should both like to take this opportunity of thanking our Egyptian colleagues for their friendliness and the kind hospitality with which they received us.

\section{SUPERSONIC CRIES OF BATS}

\section{By $D_{R}$. DONALD R. GRIFFIN}

\section{Hervard University} certain questions which I believe can be answered on the basig of new data resulting from a continuation of the inyestigations in which Dr. Robert Galambos and I were engaged before the $\mathrm{War}^{3,4}$. The bat's ability to avoid obstacles depends upon a method of pepception which I have called 'echo-location', or the location of objects by means of echoes ${ }^{5}$. The bats which we studied emit for this purpose short pulses of sound and hear the echoes which return from any solid object in their path. The emitted sound has a frequency of approximately 50 kilocycles per second, and hence is virtually inaudible to human ears. Many blind men also seem to use some form of echo-location based on audible sounds, for they can often detect obstacles at a distance, but lose this ability if their ears are stopped, or if they are distracted by loud noises ${ }^{6}$. Radar and the various underwater acoustic devices which locate distant objects by means of echoes are also examples of the general process of echo-location.

It is unfortunate that so few biologists have had access to the instruments needed to detect and study high-frequency sounds. The Noyes-Pierce sonic amplifier which we used during 1938-41 is described in the literature? ${ }^{7}$ but it has not been produced commercially. Recently I have been using a combination of commercially available instruments consisting of a condenser microphone (Western Electric $640 \mathrm{~A}$ ) followed by a cathode follower stage and several stages of voltage amplification until the sound waves emitted by the bat can be reproduced on the face of a cathode ray oscillograph. The apparatus was in part purchased with the aid of a grant from the Elisabeth Thompson Science Fund, and in part loaned by the
Psycho-acoustic Laboratory of Harvard University. I hope that similar apparatus will be used by others interested in the sounds produced by bats.

Since Prof. Hartridge was the first to suggest that bats might guide their flight by means of highfrequency sounds, it is gratifying to find that he is again taking an active interest in the problem. It is to be regretted, however, that his stimulating theoretical analyses could not have been accompanied by first-hand experience with bats in the laboratory, for I feel that this would have modified some of his conclusions. For example, the description of the sounds produced by bats is needlessly complex because the supersonic pulse, the faint audible click and the audible buzz are considered as three distinct entities, for each of which a separate source must be postulated. As pointed out in our 1942 paper ${ }^{4}$, the supersonic pulse and the click always occur simultaneously, the buzz being merely the rapid repetition of the click at rates as high as sixty per second. The audibility of these pulses of sound varies somewhat depending upon the condition of the bat, and it probably varies from species to species. Dijkgraaf ${ }^{8}$ discovered the process of echo-location independently without the aid of any apparatus by hearing bats emitting what he describes as a rattling sound when. ever they were orienting themselves, either in flight, when crawling or when at rest. He used three species of bats, rather closely related to those we studied (Myotis daubentonii, M. emarginatus and Pipistrellus pipistrellus); and it seems likely that his "rattling sound" is what we described as the buzz.

Thus the bat emits for purposes of echo-location a bundle of sound waves which is capable of stimulating both the human ear (maximum sensitivity at about $3 \mathrm{kc}$. and upper limit about $20 \mathrm{kc}$.) and also a physical detector (the Noyes-Pierce apparatus) which is sharply tuned to $50 \mathrm{kc}$. While the audible click and buzz are faint sounds, the supersonic pulse is rela. tively intense (roughly 10-50 dynes/cm. ${ }^{2}$ at the bat's mouth).

A modulated supersonic sound is not ordinarily audible even though the frequency of modulation lies within the range of the human ear, so that two possibilities suggest themselves to account for the bat's audible click : (1) Part of the bat's ery might consist of $50 \mathrm{kc}$. waves and the remainder of waves in the audible range. This would involve a change in frequency during the pulse from $50 \mathrm{kc}$. to some frequency below $20 \mathrm{kc}$. (2) Since the bat's pulse is of short duration, a Fourier analysis would reveal that energy was scattered to both higher and lower frequencies. Thus the abrupt starting and stopping of the bat's supersonic cry might stimulate our ears even though a steady sound of $50 \mathrm{kc}$. is inaudible. In addition to the transients introduced by the brevity of the pulse, one should also consider in this connexion the non-linearity of the human ear at high intensities ${ }^{9}$, which would tend to rectify the brief burst of supersonic sound into a single low-frequency wave. The second alternative is attractive, because it does not require a separate mechanism to produce the audible click.

To decide between these alternatives it is necessary to have an accurate picture of the actual sound waves present in the bat's pulse, and I have recently obtained such pictures by photographing the record of the bat's cry obtained on a cathode ray oscillograph. This work is still in a preliminary stage; but in view of the discussion in Nature it seems worth while to reproduce here four typical pictures of the pulses used by 